\section{Vascular volume monitoring with pulse oximetry during paediatric anaesthesia}

\section{To the Editor:}

Pulse oximetry represents an important tool for monitoring oxygenation, detecting hypoxaemia, and possibly reducing potential life-threatening events. ${ }^{1-4}$ Few studies, however, have examined the information provided by the plethysmographic component of the monitor. We report an important observation of the Nellcor N-100 (Haywood, CA) pulse oximeter's plethysmographic function which aids assessment of paediatric intraoperative volume status.

A $2.0 \mathrm{~kg}$ ten-week-old male infant presented for exploratory laparotomy to rule out small bowel obstruction and to undergo repair of a prolapsed ileostomy. Following surgical assessment, the lethargic infant was taken to the operating room where a $25 \mathrm{ml} \cdot \mathrm{kg}^{-1}$ lactated Ringer's (LR) IV fluid bolus provided further rehydration. An ECG, BP cuff, oesophageal stethoscope, and a pulse oximeter (Nellcor $\mathrm{N}-100$ with a neonatal $\mathrm{N}-20$ probe) attached to the right thumb served as monitoring devices. After administering atropine $0.01 \mathrm{mg} \cdot \mathrm{kg}^{-1} \mathrm{IV}$, a rapid sequence IV induction using $1 \mathrm{mg} \cdot \mathrm{kg}^{-1}$ ketamine and $1.5 \mathrm{mg} \cdot \mathrm{kg}^{-1}$ succinylcholine proved uneventful. Maintenance anaesthesia included isoflurane, pancuronium bromide, and an air/oxygen mixture. Ventilation was manually controlled through a Mapleson- $D$, humidified, infant breathing circuit at a rate of 30 to $40 \mathrm{bpm}$. The tidal volume was determined by visual observation of chest expansion and measured peak inspiratory pressure was maintained at $16-20 \mathrm{~cm} \mathrm{H}_{2} \mathrm{O}$. Five per cent dextrose in LR was administered at a rate of $8 \mathrm{ml} \cdot \mathrm{hr}^{-1}$ for maintenance and $L R$ given at $10 \mathrm{ml} \cdot \mathrm{kg}^{-1} \cdot \mathrm{hr}^{-1}$ for estimated third-space fluid loss. Estimated blood loss $(10 \mathrm{ml})$ was replaced with $L R$ in a 1:3 ratio. Approximately one hour into the otherwise uneventful anaesthetic course, the inspired isoflurane concentration required to maintain systolic blood pressure between 55 and $70 \mathrm{mmHg}$ decreased from 0.5 to 0.2 per cent. Subsequently, the pulse oximeter began skipping pulsations intermittently and displayed a pulse readout 30 to 50 per cent lower than the ECG count. Concurrent decreases in systolic blood pressure were noted but there were no decreases in heart rate. During a brief pause $(10-15 \mathrm{sec})$ in positive pressure ventilation, oximeter pulsations returned in full. Following the slow (1-2 $\mathrm{min}$ ) administration of two $10 \mathrm{ml} \cdot \mathrm{kg}^{-1}$ LR fluid boluses, the intermittent skips of the oximeter ceased despite continued positive pressure ventilation. The remainder of the case proceeded without problems and the child recovered uneventfully.
The renal and cardiovascular physiology of neonates and infants requires meticulous intraoperative vascular volume assessment and fluid management. ${ }^{5-7}$ In neonates, central venous pressure monitoring is usually reserved for more extensive procedures; estimates of vascular volume and tissue perfusion are dependent upon more gross measurements. Before the widespread use of intraoperative pulse oximetry, clinicians frequently used transcutaneous oxygen $\left(\mathrm{TcO}_{2}\right)$ electrode monitoring to measure tissue oxygenation in neonates. ${ }^{8}$ Observations made during $\mathrm{TcO}_{2}$ monitoring also demonstrated its ability to assist in determinations of cardiovascular status and tissue blood flow. ${ }^{9,10}$ We have become increasingly aware of the value of pulse oximetry in detecting early intraoperative hypovolaemia in infants and neonates.

Our case describes a typical situation during neonatal surgery in which a pulse oximeter initially functions well intraoperatively, then begins skipping beats, and eventually performs only intermittently. At this point, the anaesthetic team attempts to "readjust" the now "nonfunctioning" oximeter. If instead, positive pressure ventilation is briefly interrupted (i.e., for $15-20 \mathrm{sec}$ ) and the oximeter returns to normal or more constant function, the problem may be hypovolaemia with poor extremity blood flow accentuated by a ventilatory induced decrease in venous retum. The careful administration of fluid boluses $\left(10 \mathrm{ml} \cdot \mathrm{kg}^{-1}\right)$ will often restore perfusion and oximeter function.

The Nellcor $\mathrm{N}-100$ pulse oximeter uses its plethysmographic mechanism to determine pulsatile arterial flow, thereby allowing it to disregard non-pulsatile light absorption. ${ }^{2}$ Variation in arterial pulse wave amplitude, as produced by positive pressure ventilation, frequently appears in arterial line tracings of hypovolaemic patients. These pulse variations may reflect variations in stroke volume. Such variation may additionally occur in patients requiring or receiving excessive inspiratory pressures. The Nellcor N-100 monitor interprets the diminished pulse wave as an artifact and fails to give a signal. We have found this internal check of the monitor helpful in detecting early low-perfusion states in neonates.

The newly marketed Nellcor $\mathrm{N}-200$ with C-LOC ${ }^{\circledR}$ uses the ECG to "lock-in" on the arterial pulse wave. This helps reduce loss of monitor function which may occur postoperatively with patient motion during awakening and shivering, and extremity vasoconstriction from hypothermia or poor perfusion. Restricted motion and administration of vasodilating anaesthetic agents minimize such factors intraoperatively. We continue to use the nonECG-determined oximeter intraoperatively, since the described clinical observation aids in the intravascular volume assessment and fluid management of neonates and small children. 
In conclusion, we believe the intermittent function of the Nellcor $\mathrm{N}-100$ pulse oximeter noted during positive pressure ventilation associated with hypovolaemia in neonates and small children represents an important clinical observation which can help guide intraoperative fluid management. Anaesthetists should use this and other clinical signs to provide appropriate fluid administration, since these patients tolerate intravascular volume excesses and deficits poorly.

Daniel J. James MD

Raeford E. Brown, Jr. MD

Department of Anesthesia

Wake Forest University Medical Center

300 South Hawthorne Rd.

Winston-Salem, NC 27103

\section{REFERENCES}

1 Yelderman $M$, New $W J r$. Evaluation of pulse oximetry. Anesthesiology 1983; 59: 349-52.

2 Yoshiya I, Shimada Y, Tanaka K. Spectrophotometric monitoring of arterial oxygen saturation in the fingertip. Med Biol Eng Comput 1980; 18: 27-32.

3 Cooper JB, Cullen DJ, Nemeskal $R$ et al. Effects of information feedback and pulse oximetry on the incidence of anesthesia complications. Anesthesiology 1987; 67: 68694.

4 Tyler IL, Tantisira B, Winter PM, Motoyama EK. Continuous monitoring of arterial oxygen saturation with pulse oximetry during transfer to the recovery room. Anesth Analg 1985; 64: 1108-12.

5 Leake RD, Zakauddin S, Trygstad CW, Fu P, Oh W. The effects of large volume intravenous fluid infusion on neonatal renal function. J Pediatr 1976; 89: 968-72.

6 Dierdorf SF, Krishna G. Anesthetic management of neonatal surgical emergencies. Anesth Analg 1981; 60: 204-15.

7 Friedman WF. The intrinsic physiologic properties of the developing heart. Prog Cardiovasc Dis 1972; 15: 87111.

8 Peabody JL, Willis MM, Gregory GA, Tooley WH, Lucey $J F$. Clinical limitations and advantages of transcutaneous oxygen electrodes. Acta Anaesthesiol Scand (Suppl.) 1978; 68: 76-82.

9 Tremper $K K$. Transcutaneous $\mathrm{PO}_{2}$ measurement. Can Anaesth Soc J 1984; 31: 664-77.

10 Tabata BK, Kirsch JR, Rogers $M C$. Diagnostic tests and technology for pediatric intensive care. In: Rogers MC (Ed.). Textbook of Pediatric Intensive Care. Baltimore, Williams \& Wilkins, 1987; 1424-5.

\section{Reduction of pain on injection caused by propofol}

To the Editor:

Propofol often causes pain on injection,' which may be diminished by the prior injection of fentanyl. ${ }^{2}$ If propofol is the anaesthetic of choice, as in day-cases, alfentanil may be a more appropriate analgesic. We studied 149 ASA physical status I and II patients about to undergo general, gynaecological or orthopaedic operations after informed consent and ethics committee approval.

A vein in the dorsum of the hand was cannulated with a 17G PVC cannula and if the first attempt was unsuccessful $a$ vein in the forearm or antecubital fossa was cannulated.

Patients were randomly allocated in a double-blind fashion to receive two $\mathrm{ml}$ of a solution containing either fentanyl $50 \mu \mathrm{g} \cdot \mathrm{ml}^{-1}$ (group F), alfentanil $0.5 \mathrm{mg} \cdot \mathrm{ml}^{-1}$ (group A) or saline 0.9 per cent (group S). Oxygen was administered for three minutes after propofol $1.5 \mathrm{mg} \cdot \mathrm{kg}^{-1}$ was given over $25 \mathrm{sec}$. Patients were asked if they felt any pain or discomfort on propofol injection (direct pain, Table). One hour after awakening patients were questioned again about pain during the propofol injection and again $24 \mathrm{hr}$ later (both included in late pain, see Table).

Significantly fewer patients complained about pain on injection of propofol if they had received an analgesic but

TABLE Demographic data and results in patients given either fentanyl, alfentanil or saline prior to propofol

\begin{tabular}{|c|c|c|c|}
\hline & Fentanyl & Alfenranil & Saline \\
\hline$n$ & 49 & 50 & 50 \\
\hline \multicolumn{4}{|l|}{ Age yr } \\
\hline$( \pm \mathrm{SEM})$ & $37 \pm 11(18-59)$ & $35 \pm 11(19-55)$ & $36 \pm 9(19-49)$ \\
\hline Male/female & $18 / 31$ & $15 / 35$ & $19 / 31$ \\
\hline \multicolumn{4}{|l|}{ Injection site } \\
\hline - hand & 40 & 42 & 42 \\
\hline - arm & 9 & 8 & 8 \\
\hline \multicolumn{4}{|l|}{$\begin{array}{l}\text { Pain } \\
- \text { direct }\end{array}$} \\
\hline - hand & $6^{*}$ & $4 \dagger$ & 15 \\
\hline - arm & 0 & 0 & 1 \\
\hline $\begin{array}{l}\text { - total } \\
\text { - late }\end{array}$ & $6^{*}$ & $4 \dagger$ & 16 \\
\hline $\begin{array}{c}\text { - total } \\
\text { - overall }\end{array}$ & 2 & 4 & 4 \\
\hline - hand & 8 & 8 & 17 \\
\hline$-\operatorname{arm}$ & 0 & 0 & 3 \\
\hline- total & $8^{*}$ & $8^{*}$ & 20 \\
\hline
\end{tabular}

${ }^{*} P<0.05, \dagger P<0.01$ compared with saline. 